\title{
Negotiating Identity and Belongingness as Migrant Youth: The Chameleon and Butterfly Strategies
}

\section{Beatrice Okyere-Manu \\ ORCD iD: https://orcid.org/0000-0003-2735-9227}

\begin{abstract}
Literature on the issue of identity faced by second-generation migrants (children, youth or young adults) abounds mostly from the Western perspective. Scholars in international migration and ethnicity have argued that second-generation migrants find themselves in two worlds, where the culture of their heritage and that of the host society are not identical. This implies that they live in two worlds. However, in this ethnographic paper, I argue that they rather live in three worlds and are thereby influenced by tri-cultural based conflict. In addition, I argue that some of these youth are further able to develop a subculture to enable them to cope with the expectations of the three worlds. In this paper, I first present the normative bicultural argument exposing the challenges that they are confronted with. The second section argues for the third socio-cultural world: the hybrid culture in their homes. Notwithstanding the challenges that they face, the third section explores the Chameleon and Butterfly strategies that they use to navigate these three socio-cultural worlds.
\end{abstract}

Keywords: chameleon strategy, butterfly strategy, hybrid culture, second generation migrants, identity and belongingness

\section{Introduction}

Migration, whether internal or international, continues to be a topical issue globally. A United Nations document revealed that in 2016, there were over 244 million international migrants and about 740 million internally displaced adults 
and children globally (2016). The inference is that it is possible that the number might have increased drastically by now. A large body of literature that investigates migration, particularly migration to the West, abounds. Most of these interrogate the push and pull factors, citing the following as the main causes: conflicts, political instability, changes in climate conditions and the search for greener pastures (Parkins 2010; Watters 2008; Suárez-Orozco \& SuárezOrozco 2001). Other scholars have exposed the challenges faced by migrants in the host countries; these include mental health, physical health, positive and negative effects of migration on families, and the economy, the role of government and other stakeholders (Bempong et al. 2019). Through empirical studies, others have also argued that the children and youth of migrants are often confronted with issues of identity, and belongingness in two worlds (Dusi et al. 2014). Hence, they have to navigate between the socio-cultural expectation of both the host country and that of their heritage. Such expectation often puts pressure on them, especially as they try to navigate their identity and belongingness through these worlds.

This study draws on an ethnographic research methodology to explore how second-generation migrant youth navigate their belongingness in the three cultural worlds.

Being a migrant with three children, who have grown up in the context of migrations, I have had the opportunity to observe how they navigate their identity and belongingness. When we migrated to Pietermaritzburg, South Africa as a family in 1996, they were still very young (six, four and two years old). They are now young adults, making them an appropriate study population. In addition to the experience gained from my children's daily experiences, I have also had the opportunity to observe their migrant friends as well. As a migrant mother and an 'aunty' to most of my children's migrant friends, I became part of their daily lives through offering some of them daily lifts to and from school. I looked after some in our home after school; some even attended special days and activities at school with us, etc. There were times when we had about four migrant youth in our home, especially during the school holidays. The cordial relationship that developed between the migrant youth enabled me to immerse myself in their daily experiences.

In addition, my years of lecturing Ethics, which serves as an elective module for most of the disciplines at the University of KwaZulu-Natal (UKZN) in Pietermaritzburg, South Africa has presented me with an opportunity to interact with many migrant youth. UKZN attracts a number of 
international students, and I have had the opportunity to observe, study and interact with a number of second-generation migrant students who enrol in some of the modules in our department, on a personal level. The experiences gained from these three study populations is what Kusenbach (2003) refers to as a 'go-along' ethnography. It is a methodology whereby the researcher accompanies the participants as they go about their daily activities, whatever it may entail. This can take place even over a period of years.

The categories of second-generation migrants that informed the current study include children born elsewhere but who eventually accompanied their parents to South Africa. There are also those born in South Africa by nonSouth African parents, however, both parents come from the same country. Then there are those who were born in South Africa from two migrant parents who are from two different countries. In addition, there are those born in South Africa where one parent is a South African and the father, a migrant. In all, about 20 second-generation migrants were studied over a period of about 10 years. Even though the focus of the study is an ethnographic study of secondgeneration migrants in Pietermaritzburg, their experiences may resonate with most second-generation migrants in the rest of South Africa.

In this article, I advance two arguments: first, I argue that migrant children grapple with three worlds, which is somehow contrary to the popular bi-cultural claim. Second, I maintain that most second-generation migrant youth are able to navigate these worlds using a possible sub-culture as a coping mechanism to negotiate their identity and membership.

\section{Bi-cultural Social Arguments}

There has been a growing concern that second-generation migrants face a number of bi-cultural challenges and this has led to a large body of literature investigating second-generation migrants, particularly those who migrate to the West as indicated in the introduction of this paper. Scholars such as LorickWilmot (2014), Trew (2009) and Portes and Rumbaut (2001) have explored the experiences of second-generation migrant youth, exposing the challenges they face in navigating their identities and belonging in their homeland and host land. The common thread that runs through all these studies is the deep sense of insecurity that second-generation migrants face, which seems to come from the constant feeling of being an outsider and a stranger whether in the host land or the homeland. Growing up in a foreign land with their parents 
whilst the rest of the extended family is in another country creates conflict within second-generation migrants. This is despite technology, which has improved communications and general connections. It must be noted that the lack of regular involvement and identifying with both mainstream and heritage cultures affects their identity (Berry 1997; LaFromboise et al. 1993). Writing from the Zimbabwean context, Mpumelelo Moyo (2017: 15) says the following about migrant children, 'they find themselves in a luminal state, not fully accepted in their host countries, but also castaways in the land of their parents ... and are often spectators of "their" own culture'. The experiences of my three children and their friends attest to the above fact.

What has been a common concern whenever there is a discussion about the homeland, is that despite the long stay outside the homeland they longed to maintain strong links with their heritage especially in issues around family, relationships and nationalism (Naidoo \& Davis 1988). However, as secondgeneration migrants away from their homeland, they struggle. Some of the youth that I studied visit their homelands on a regular basis while others rarely do so. For those who go home regularly, though they often share their experiences with enthusiasm, they also often share challenges such as being exposed to mosquitoes, snakes, the extreme weather conditions, and lack of running water.

The major challenge that often stands out is the feeling of being an outsider among extended family members. They often describe the feeling as going for an 'interview' where everyone around them watches them to see how they behave. For example, going to the homeland for the first time was very stressful for my children, as second-generation migrants. Weeks leading up to the journey were very disturbing to them even though there were a series of discussions explaining what to expect in the homeland, they had deeper concerns than we had anticipated as parents. One of the major concerns that they were wrestling with was the issue of acceptability. They were anxious to know whether they would be accepted by the extended family and the neighbours or not. In addition, they wondered what the expectation of the extended family would be. They were also concerned about what was going to happen if they failed to measure up to the expectations of their family in the homeland. Another major cause of anxiety was on the issue of language and the fact that they were not fluent in the native language, and they wondered how they could communicate with family members since they were not very fluent in any of the local languages. 
Then there was the issue of food, growing up in the host land, they were not used to most of the traditional food which is the staple diet in the homeland. They used to ask what behaviour was acceptable in the homeland and whether the extended family in the homeland would approve of or frown upon certain behaviour. Whilst they had enjoyed listening to family histories and cultural practices, they perceived that experience as theoretical because they had often felt alienated from the family. These and many concerns increased the social and cultural conflict within them. In the end, it pushed them to work hard to feel a sense of acceptance and belonging when we finally arrived, which in itself was problematic. The experiences of my children described above confirms the narrative of social and cultural conflict that most migrant youth face. A study by The International Organization for Migration (IOM), aptly describes the challenges that second-generation migrants face stating that they encounter:

Psychosocial difficulties such as feelings of abandonment, low selfesteem, anger, depression and/or material obsession that could result in behaviour problems. School performance drops and some children even lose the right to education, lack access to health care as some migrants do not have the ability to register new-borns - these are some noticeable effects of migration on children who are sometimes vulnerable to sexual abuse and exploitation (IOM 2010:10).

My research findings concur with the issues raised in the above -mentioned study, I remember a parent of one of the study participants lamenting that any time her daughter was sad, she would start crying and say that she would like to go back to the homeland. This state of affairs affected the child emotionally to the point that they were forced to send her home every vacation. She struggled to make friends at school, it affected her academic work and finally, after high school the girl went back to the homeland for good. When my children were in primary school, they used to have a period on the timetable where they had to share where they spent the weekend, as well as tell the class about their families. This exercise always presented emotional difficulties for them, because the locals shared their stories of spending weekends with their extended families, especially grandparents. My children had no stories of visitation to tell.

Another interesting observation I made during the study is that even 
when the youth who have never visited the homeland also taste some of challenges through extended family members to the host land. These relatives often try to impose certain values and practices on them, to which they are unfamiliar. This imposition of values is not only limited to relatives who visit but extends to those who remain in the homeland and provide input over the phone. In addition, most of the study participants bemoaned that extended family members often rebuke them for their social lives, tracked on social media.

In the host land too, second-generation migrants face many sociocultural vulnerabilities and different forms of alienation such as xenophobia, cultural dislocation, exploitation, social discrimination and identity crisis (Global Migration Group (GMG) 2013: 10). The GMG findings resonate with the concerns of most of the study population. They often share their experiences of alienation, in the form of xenophobia with one another. Protector et al. (1978: 1605) define xenophobia as the 'unreasonable pathological dislike of foreigners or strangers'. This dislike is evident in the way most of their local schoolmates related to them. In the experiences of the study population, they were given names such as 'amakwerekwere' which is a derogatory name given to foreign nationals residing in South Africa (Muller 1999: 72). In addition, they were exposed to various forms of bullying and intimidation. An example is an experience that one of the study participants, whose pseudonym is George, shared. He was moved from a 'B' Class to an 'A' class at a local primary school. On his first day in the new class, a fellow pupil approached him and warned him that he does not belong in the new class. George was so intimidated that he refused to go to the class until his parents intervened.

On the issue of the challenge of aggression, there was a conflicting experience among the study population. Some of them mentioned having experienced some form of aggression, particularly at high school and at university: the forms of aggression range from face-to-face confrontation to intimidation by local students and even by some of the university personnel. Others denied having experienced any form of aggression. They claimed that they were/are friends with most of their schoolmates.

Another conflicting experience among the study population centred around on language. Some were confronted with the challenge of not being able to speak any of the South African native languages fluently, as well as not being familiar with the local culture. This background not only became a barrier in making friends but also led to name-calling. This attitude continu- 
ously makes it difficult for some of them to make friends, even as adults, therefore they have opted to befriend mostly other second-generation migrants. This is because they share similar experiences and challenges; the similarity of experiences naturally connect them to each other.

\section{The Tri-cultural Social Space}

As noted above, the ethnographic methodology offered me the best chance of experiencing the day-to-day life experiences of the study population as an insider. In this section, I argue that in addition to the popular bi-cultural challenges and experiences discussed above, there is a third powerful space that presents a third socio-cultural conflict in the lives of second-generation migrant youth. This is a hybrid cultural space within the family home where they live with their parents in the host land. In explaining the concept of hybridity, Jonathan Rutherford says that 'for me the importance of hybridity is not to be able to trace two original moments from which the third emerges, rather hybridity to me is the "Third Space", which enables other positions to emerge' (1990: 211). The above quotation suggests that this hybrid culture consists of a blend of cultures between the homeland and the host land. The culture within this hybrid space is so subtle; however, it has more powerful influence on the second-generation migrants than either host land or the homeland. From the study, it is evident that this third space is characterised by the cultural expectation of parents, which is brewed within the four corners of the home. Describing the concept of hybridity further, Ankie Hoogvelt believe that hybridity is:

celebrated and privileged as a kind of superior cultural intelligence owing to the advantage of in-betweeness, the straddling of two cultures and the consequent ability to negotiate the difference (1997: 158).

As a migrant parent, I can attest to the fact that migration changes most parents' cultural worldview over time and they try to model a sub-culture in the third space, away from the dominant host culture though not in totality. As a blend of the host and the homeland socio-cultural practices, it is evident in simple manners and etiquettes such as dressing, ways of speaking and choice of language, respect and attitude towards the elderly, hairstyles and general attitude to work, whether at school or chores at home. The study group agreed 
that within this third space, there is a constant reminder from parents of "where they come from' and the fact that they are foreigners and as such they need to behave differently from the host youth. Often, this hybrid culture presents conflict between parents and migrant youth in terms of not adopting the culture of the host country (Masheti 2014). This is because in most cases the hybrid culture is different and may not be fully endorsed by the host land. It is sometimes frowned upon or perceived as different and strange by the host community.

In the same way, the external family members in the homeland often think that the young people are being adulterated by foreign norms and values. As a result, the norms governing this hybrid culture are constantly renegotiated between the parents and their youth in migration. Most parents keep rewriting the rules of the home in the host countries because the legal system concerning children in the South African context often disarms authoritarian parental practices and family rules, making space for young people to manoeuvre. Most of the time, migrant parents are ambivalent about their children's assimilation into the South African cultures and they communicate these mixed feelings to their children through verbal and non-verbal means. They want their children to fit in, but not too much thus creating a blurred line between being too South African and too foreign. The lack of clear-cut boundaries often puts a strain on the young people in figuring out their identity and belongingness. This is particularly true on issues of autonomy and privacy in communication, boundaries and limitations of young migrants. In addition, it becomes extremely difficult when they leave home to go to university and even when they join the workforce, as they now have to figure out who they are outside the hybrid culture. Ironically, the new world around them makes assumptions about who they are. Their new local friends at university and even in the workplaces become curious about how and why they do things differently. However, they find solace in other young migrants around them, since they seem to share similar experiences.

\section{Surviving the Social and Tri-cultural Spaces: The Chameleon Strategy}

Despite the weight of the social and tri-cultural spaces on the migrant youth, a few studies have foregrounded that some migrant youth are able to persevere and survive the negative challenges (Isseri et al. 2018). Others such as Hemson 
(2011), Hlatshwayo and Vally (2014) have argued that because most migrants come from vulnerable economic backgrounds and they aim to improve their economic and social circumstances, they motivate and support their children to excel at school. From the experience gained through studying the secondgeneration migrants, two distinct strategies that they use were observed. They are I have called the chameleon and the butterfly strategy. This section discusses the chameleon strategy.

When my children were in school, my eldest son mentioned that he developed a slogan to help him navigate through the different worlds, and he called it 'live a quiet life', a personality trait often exhibited by introverts. Therefore, whether he was at school or at home in the host land or homeland, he quietly navigated his identity and belongingness. Mudore says that 'Introverts get their batteries charged from the inner world of ideas and enjoy being alone' (2002: 1). This point came out strongly in my observation of some of the migrant youth in this study. Describing the characteristics of introverts, Salahi Akbar reiterated Behahani et al. that, 'Introverts, for instance, have characteristics such as shyness, bashfulness and bad-temperedness' (2010: 4017). This strategy is what I refer to as the Chameleon strategy because it shares the same characteristics of the reptile chameleon. Over the years, I have observed most migrant youth exhibiting the same characteristics.

Just like the chameleon, second generation migrants live in a multifaceted, dynamic and a highly competitive environment that demands a carefully planned strategy for survival. Nevertheless, the chameleon's different features make it possible for it to cope in its dangerous surroundings. In the same way, most migrant youth seek to survive, and make the most of their new environment amidst challenges such as bullying, do's and don'ts, constant reminder of being an outsider, pressure to be the same as everyone else and also the pressure to be different, the need for acceptance, and generally unfriendly attitudes. They therefore adopt a situational identity to benefit their social context. Sultana Choudhry (2010) reiterated this when she studied interethnic young people in the United Kingdom. She confirms that her study population: 'tended to switch between different features of their identities that is they emphasised different aspects, depending on whom they were with or the situation they were in'. Just like the study population in this current study, they are able to switch identities to best suit the situation. It must be noted that the chameleons have both positive and negative characteristics, in this article three prominent features of the chameleon will be used as an analogy in 
analysing how some second-generation migrants cope in the three worlds around them.

The first prominent feature is that the chameleon can change its colour to suit the environment around it. By nature, a chameleon studies its environment and blends in slowly and carefully. It is able to blend in with its environment within seconds by changing its colour. This adaptive strategy makes it to stand out among all reptiles. Gary Ferguson and Kenneth Kalisch say that chameleons have been called 'masters of camouflage, using various abilities to pass almost unseen through the surrounding areas. They rest motionless or move slowly and deliberately with a rocking gait so they are not seen by potential predators' (2007: 4). The blending in of the chameleon with its environment is a strategy used to lure its predators away, to its advantage.

In terms of the study population, some are able to slowly change through a wide range of adaptation strategies to suit any of the social and tricultural spaces described above, in order to navigate their belongingness. For instance, they keep tweaking and adapting to new strategies to help them cope. I observed that they quietly study the prevailing culture/s before adapting to the dominant culture, and they do so slowly and meticulously. These secondgeneration migrants use this strategy to handle pressures from all three worlds. The chameleon uses this feature to move over thorns, rough wood, leaf tips, stones and even muddy and slippery surfaces. A critical observation of this strategic movement portrays both positive as well as negative results. The chameleon is always ready and willing to adapt to new opportunities that may arise, just like the category of second-generation migrants under study. However, the time taken to study the environment before making their moves often leaves them on lonely paths, which makes them more vulnerable to peer pressure, sometimes exposing them to being bullied. One can interpret this feature as unreliable, especially with the tendency to swing from one adaptation strategy to the other to avert attention from themselves.

Another important feature exhibited by the chameleon is its keen situational awareness. The chameleon is known for its distinctive eyes with good eyesight that enables it to see prey and other small animals even from afar. The eyes have a 360-degree arc of vision, allowing them to look in two directions at the same time. Even though the chameleon has no outer ears and cannot hear much, it is not deaf, it is cognisant of action and sounds (Ferguson \& Kalisch 2007: 4).

In the same way, I have observed that most second generation migrants 
are very sensitive to and vigilant of their environment. In their quest to be accepted, they often find themselves interpreting not only words but also actions before making decisions within the three worlds. This same feature enables them to adjust to the requirements of the operating culture by focusing on its needs. Most second-generation migrants do not only focus on one aspect at a time but show multi-pronged abilities to ensure effectiveness of response and adjustments. In my view, if this feature is not well-monitored, it can lead to confusion, misunderstanding and misinterpretation of behaviour portrayed by others around them. This is because some actions and even sounds in any of these worlds can be misinterpreted, which may in the long run have negative effects on the identities and belongingness of these young migrants.

When hard pressed or threatened, these migrant youth can change their behaviour within seconds to confront the situation, just like chameleons. As noted by Mudore above, they tend to be bad-tempered at times. The chameleon is also able to exhibit these characteristics. In fact, besides changing colour when threatened, under extreme conditions, it can even bite. This feature often puts migrant youth on lonely paths; a lack of friends and difficulties in peer relationships are associated with increased loneliness (Nagle et al. 2003). I do agree with Nagle in that just like the youth I studied, most of them complained of having few friends at school and even around their neighbourhoods. Others preferred to have deeper bonds with their siblings rather than with outsiders.

Another prominent feature of the chameleon is in its high performance brought about by the length and flexibility of its tongue. Using its extremely long and fast tongue, a chameleon can catch insect prey at a distance. In relating these characteristics of the chameleon to the study population, it can be said that they strive for high performance and excellence in their work. Hemson (2011) and Nnadozie (2010) share the same sentiments that migrant scholars who have survived socio-cultural challenges, have used them as a drive towards success. It must be noted that they do not usually only excel academically but also in sports and all spheres of their lives in the host land.

\section{The Social Butterfly Strategy}

From the experience gained from the study population, another strategy that some of the second-generation migrants use to navigate their identity and belongingness is the social butterfly strategy. This is where the migrant youth intentionally become friendly with everyone around him or her. For example, 
unlike the strategy used by my two sons and some of their friends mentioned above, my daughter on the other hand exhibits the butterfly characteristics. She likes to network and can make friends with people around her quite easily. As Baumeister and Leary have observed, naturally, human beings are motivated to form and maintain networks to achieve their need to belong (Baumeister \& Leary 1995). The inference here is that forming and developing networks is a natural phenomenon, however, for some individuals they are able to do this with ease; this is the characteristic often exhibited by extroverts. Mudore believes that "extroverts get their energy from people and are renewed by being around others' (2002:1). These individuals tend to maximise their social capital by befriending people and seem to attract friends with similar characteristics. In terms of the study population, they attract both migrants and locals quite easily. For my daughter, in particular, an important contributing factor to this strategy is her flair for languages. This enables her to be accepted quite easily among her peers.

Salehi Akbar (2002: 1), reiterated Ghangi et al. 1994 that 'cheerfulness, witticism, sociability and good humour are among some of the characteristics found in extroverts'. I have observed these characteristics in both my daughter and in some of the study population as well.

One advantage of the butterfly strategy is that it affords secondgeneration migrants' positive inclusion in almost any group, making them popular among their friends with a 'considerable degree of positive interaction' (Verma et al. 1994: vii). Just like the butterfly that flies from flower to flower, leaving pollen wherever it visits, social butterflies make friends easily and often work hard to leave their mark on people with whom they come into contact. They are adaptable and are more likely to be accepted as they are in terms of their interest in sport, music, fashion and knowledge acquired through reading.

The down-side of this strategy, as expressed by the study population is that it places them in vulnerable situations of disappointment, from their friends and negative peer pressure. These factors can have a devastating impact on them, however most of them are able to survive these migration pressures as they mature.

\section{Conclusion}

In this ethnographic study, I have argued that second-generation migrant youth 
face tri-cultural social challenges from three worlds instead of the popular bicultural challenges, as stated by most scholars. The three worlds mentioned include: the homeland, the host land and a hybrid space with their parents in the host land. It has been noted that the developing world equally presents challenges that affect their identity and belongingness. Through observation and experiences of the study population, two main strategies that they use to navigate their identity and belongingness were discussed. They include the chameleon and the social butterfly strategies. The study further noted that the chameleon strategy includes characteristics which are similar to those displayed by introverts. The features of the chameleon such as its ability to change colours, its high level of performance through its long, darting tongue, its sharp eyes and slow movements is akin to how some migrant youth navigate their identity and belongingness successfully through the three worlds.

Other second-generation migrant youth use the butterfly strategy to navigate their identity and belongingness in the tri-cultural social worlds. The features of a butterfly with its ability to move from one flower to the next is similar to how these migrant youth operate. They become friends with all their acquaintances. Despite the challenges of disappointment and the peer pressure that come with this strategy, it seems that most second-generation migrant youth have survived the process and have emerged successfully.

\section{References}

Akbar Salehi 2010. The Study of the Relationship among Personality Factors (Introversion, Extroversion) of Students and their Effects to Selecting a Good Teacher. Procedia Social and Behavioral Sciences 2: 4016 - 4020. https://doi.org/10.1016/j.sbspro.2010.03.633

Baumeister, R.F. \& M.R. Leary 1995. The Need to Belong: Desire for Interpersonal Attachments as a Fundamental Human Motivation. Psychological Bulletin 117: 497 - 529.

https://doi.org/10.1037/0033-2909.117.3.497

PMid:7777651

Bempong, N-E, D. Sheath, J. Seybold, A. Flahault, A. Depoux \& L. Saso 2019.

Critical Reflections, Challenges and Solutions for Migrant and Refugee Health: $2^{\text {nd }}$ M8 Alliance Expert Meeting. Public Health Reviews 40,3. https://doi.org/10.1186/s40985-019-0113-3

PMid:30923641 PMCid:PMC6423837 
Berry, J.W. 1997. Immigration, Acculturation and Ddaptation. Applied Psychology 46: 5 - 68.

https://doi.org/10.1111/j.1464-0597.1997.tb01087.x

Choudhry, S. 2010. Multifaceted Identity of Interethnic Young People: Chameleon Identities. London: Routledge.

Dusi, P. G. Messetti, I. González Falcón \& N.C. Parkins 2010. Push and Pull Factors of Migration. American Review of Political Economy 8,2: 6 - 24. Dusi, P., G. Messetti, I. González Falcón. 2015. Belonging: Growing up between two Worlds. Social and Behavioral Sciences 171: 560 - 568. https://doi.org/10.1016/j.sbspro.2015.01.161

Ferguson, G., K. Kalisch \& S. McKeown 2012. Chameleons: Care and Breeding of Jackson's, Panther, Veiled, and Parson's. Irvine CA: Bow Tie Press.

Global Migration Group (GMG) 2013. Exploitation and Abuse of International Migrants, Particularly those in an Irregular Situation: A Human Rights Approach THEMATIC PAPER.

https://www.unodc.org/documents/humantrafficking/2013/2013 GMG Thematic Paper.pdf.

Hemson, C. 2011. Fresh Grounds: African Migrants in a South African

Primary School. Southern African Review of Education 17: 65 - 85.

Hlatshwayo. M. \& S. Vally 2014. Violence, Resilience and Solidarity: The Right to Education for Child Migrants in South Africa. School Psychology International 35,3: 266 - 279.

https://doi.org/10.1177/0143034313511004

Hoogvelt, A. 1997. Globalization and the Postcolonial World: The New Political Economy of Development. Baltimore: The John Hopkins University Press.

Isseri, S., N. Muthukrishna \& S. Philpott 2018. Immigrant Children's Geographies of Schooling Experiences in South Africa. Educational Research for Social Change 7,2: 39 - 56.

https://doi.org/10.17159/2221-4070/2018/v7i2a3

Kusenbach M. 2003. Street Phenomenology: The Go-Along as Ethnographic Research Tool. Ethnography 4, 3: 455 - 485.

https://doi.org/10.1177/146613810343007

LaFromboise, T., H.K. Coleman \& J. Gerton 1993. Psychological Impact of Biculturalism: Evidence and Theory. Psychological Bulletin 114: 395 412. https://doi.org/10.1037/0033-2909.114.3.395 PMid:8272463 
Lorick-Wilmot, Yndia S. 2014. Between Two Worlds: Stories of the SecondGeneration Black Caribbean Immigrant. Trotter Review 22, 1,5: 7 - 21. Masheti, N.W. 2014. Psychosocial Well-being of African Migrant Children in Ireland: A Cultural Orientation. Unpublished $\mathrm{PhD}$ Thesis, University College Cork.

Moyo, M. 2017. The Zimbabwean Crisis and the Family: Challenges and Opportunities for the Zimbabwean Church. Journal of Theology and Religious Studies 1,1: 8 - 21. Harare: Africa Institute for Culture, Peace, Dialogue \& Tolerance.

Mudore, C.F. 2002. Are you an Introvert? Current Health 2,29: 17 - 20. http://search.epnet.comllogin.aspx?direct=true\&AuthType=cookie,ip,url uid \&db=aph\&an=8727764. (Accessed on 3 August 2019.)

Muller, H.P. 1999. Encountering Recent African Migrants and Immigrants to South Africa: Towards Understanding the Role of Religion and Culture in the Reception of Recent African Migrants and Immigrants. Scriptura 68: 67 - 73. https://doi.org/10.7833/68-0-1124

Nagle, D.W., C.A. Erdley, J.E. Newman, C.A. Mason \& E.M. Carpenter 2003. Popularity, Friendship Quantity and Friendship Quality: Interactive Influences on Children's Loneliness and Depression. Journal of Clinical Child and Adolescent Psychology 32,4: 546 - 555.

https://doi.org/10.1207/S15374424JCCP3204_7 PMid:14710463

Naidoo, J.C. \& J.C. Davis 1988. Canadian South Asian Women in Transition: A Dualistic View of Life. Journal of Comparative Family Studies 19: 311 - 327. https://doi.org/10.3138/jcfs.19.2.311

Nnadozie, J.I. 2010. Exploring the Schooling Experience of Migrant Children from the Democratic Republic of Congo in South Africa. Doctoral dissertation. Edgewood, Durban: University of KwaZulu-Natal.

Portes, A. \& R.G. Rumbaut 2005. Introduction: The Second Generation and the Children of Immigrants Longitudinal Study. Ethnic and Racial Studies 28,6: 983 - 999. https://doi.org/10.1080/01419870500224109

Protector, P., R.F. Ilson, J. Ayto 1978. Longman Dictionary of Contemporary English. London: Harlow.

Rutherford, J. 1990. The Third Space: Interview with Homi Bhabha. In Rutherford, J. (ed.): Identity, Community, Culture, Difference. London: Lawrence and Wishart.

Suárez-Orozco, C. \& M.M. Suárez-Orozco 2001. Children of Migration. Cambrige, MA: Harvard University Press. 
Trew, J.D. 2009. Migration in Childhood and its Impact on National Identity Construction among Migrants from Northern Ireland, Irish Studies Review 17:3, 297 - 314. https://doi.org/10.1080/09670880903115512

United Nations (UN) 2016. 244 Million International Migrants Living abroad Worldwide, New UN Statistics Reveal.

https://www.un.org/sustainabledevelopment/blog/2016/01/244-millioninternational-migrants-living-abroad-worldwide-new-un-statisticsreveal/ (Accessed on 05 October 2021.)

Verma, G.K., P. Zec \& G. Skinner 1994. Harmony and Hostility in Multiethnic Schools. London: Falmer Press.

Watters, C. 2008. Refugee Children. Towards the Next Horizon. New York, NY: Routledge. https://doi.org/10.4324/9780203935996

Dr. Beatrice Okyere-Manu Senior Lecturer Programme Director for Applied Ethics School of Religion, Philosophy and Classics University of KwaZulu-Natal okyere-manv@ukzn.ac.za 